\title{
Brundtland takes charge and restructures the WHO
}

Immediately after taking the helm of the World Health Organization (WHO, Geneva), Gro Harlem Brundtland, a former PrimeMinister of Norway, hasembarked on a substantial restructuring of the agency which is expected to take three months to complete. The changesareaimed at streamlining an organization which has often been criticized for inefficiency.

Brundtland's first official act was to introduce new financial disclosure rules requiring all senior staff to submit forms detailing financial interests, patents, and positions held in the private sector. Sources at the WHO deny that the policy is in response to specific incidents, saying it is part of a general ethicsinitiative at the UN. "Since she's joining now and establishing a new team ... she wanted to make sure from the very beginning that there won't be any suspicion or any doubt," explains a WHO spokesman. The policy will affect a total of 21 top staff members.

In addition to initiating budgetary changes across its regional offices (Nature Med., 4; 874, 1998), Brundtland has also announced a sweeping revision to the agency's internal structure. Replacing a Cold War tradition by which the top WHO echelon of Assistant Directors General represented the Security Council member states, Brundtland and nine Cabinet members from both industrialized and lesserdeveloped countries will now preside over the agency. While the gender mix of the managing group-six women and four men-is reminiscent of Norway, where over half of all politicians are

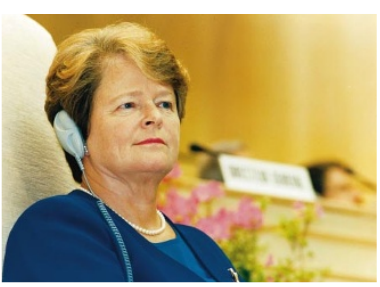

Gro Harlem Brundtland
To assist in the restructuring process, the Rockefeller Foundation, a long-standing supporter of the WHO, has donated $\$ 2.5$ million to establish the Global Health Leadership Fund. The fund is intended to provide resources for recruiting new staff to the agency, but the Foundation has not earmarked the money for any specific positions or programs. Although this is the first time that the Rockefeller Foundation has given money for administrative female, Brundtland states "I did not go for a majority of either men or women. I went for a balance of experiences. And I got it." Perhaps more significant than the presence of so many women managing the agency is the arrival of outsiders: only three of the ten Cabinet members were selected from within the WHO. The pre vious Assistant Directors General have been given temporary positions as Special Advisors, with the understanding that their contracts will not be renewed. restructuring, the Foundation's vice president, Lincoln Chen, insists that it is not a personal endorsement of the DirectorGeneral: "We want to support not simply Brundtland the person, but the performance and the potential of this very important organization." TheFoundation is now arranging additional contributions to the Fund. The government of Norway has also granted nearly $\$ 1$ million to aid the agency's restructuring.

\section{Alan Dove, New York}

\section{Who should subsidize $\mathbf{N C l}$ clinical trials?}

Cancer researchers and patient advocates have been to theUSCongressto ask for support in increasing clinical trial recruitment. Membersweretold at a SenateCancer Coalition meeting that cancer patients are reluctant to enroll in trials because, although they are not charged for the cost of the experimental drug or device, they cannot obtain insurancecoveragefor related physician and hospital charges under the trial.

Only three percent of 7.4 million Americans alive today with a history of cancer participate in any kind of clinical trial, but the National Cancer Institute $(\mathrm{NCl})$ hopes to encourage more patients to enroll by spending close to $\$ 20$ million on making moreinformation availableto the public on research results and how to get into trials.

But the question remains as to who is willing to subsidize the cost of $\mathrm{NCl}^{\prime}$ 's clinical research-the government and private insurersseem to bedeadlocked on theissue. In its FY99 budget proposal, the $\mathrm{NCl}$ said it aims to increase participation in the $\mathrm{NCl}$ supported Cooperative Treatment Trials Program five-fold over the next five years. At present around 300,000 people take part in these studies, and accommodating this increase through administrative and infrastructure changes will cost $\$ 170$ million.

However, the $\mathrm{NCl}$ maintainsthat it is the responsibility of insurers to pay for cancer study patients' routine medical care. Not surprisingly, the insurance industry disagrees. "I would arguetheinsurance system isn't the best place to subsidize this type of activity," Charles Kahn, chief operating officer of the Health Insurance Association of America told Nature Medicine. "It's not that we believe there shouldn't beexperimentation," says Kahn. "It's just a question of who should be responsiblefor it. If it's a public good, then the taxpayers ought to subsidizeit. But to havepremium payers do so indirectly is not the general agreement between premium payers and insurers." Kahn says he has no idea how much a research subsidy would add to premiums.

The American Society of Clinical Oncology (ASCO) agrees that lack of reimbursement is a big reason for low trial participation, and that severe underfunding of $\mathrm{NIH}$ trials is a major barrier. "Current funding does not reflect the true cost of research," ASCO president Allen Lichter told the Senate Cancer Coalition.

Lichter also saysthat clinical research trial

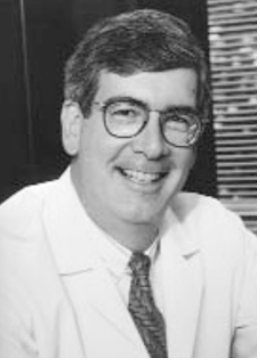

Allen Lichter proposals are not getting a fair hearing at $\mathrm{NIH}$ becausethey are being reviewed by basic scientists. ASCO has pleaded for an overhaul of this policy to no avail, says Lichter.

In hisFY99 budget, President Clinton proposed that Medicare do a pilot study on paying for patient care costs in $\mathrm{NIH}$-approved trials. It is not clear whether the proposal will survive, but it was noted by insurers, who generally line up coverage with Medicare.

Kahn insists that a federal or state mandate to cover clinical trial care costs is only a remote possibility. It has been included in only one of the 'patients' bill of rights' being considered in Congress. "I think that sooner or later it could happen, but obviously it's not on the front burner," says Kahn.

Alicia Ault, Washington, D.C. 